Revista Avances en Salud 2019; 3(2): 6-7

DOI: $10.21897 / 25394622.1660$

ISSN-e 2619-4945

\title{
El contexto situado de la mortalidad materna en el departamento de Córdoba: Una fotografía de la Mujer pobre urbana
}

\section{Situated context of maternal mortality in the department of Córdoba: A photograph of urban poor women}

\begin{abstract}
Javier Bula Romero ${ }^{1}$
La mortalidad materna es vista como una tragedia familiar y social en todas las regiones del mundo; una muerte materna, no es sólo una defunción más; es la vida de una mujer que se ausenta de su núcleo familiar (1). - Y las madres son irremplazables en una familia; cuando una de ellas muere, no sólo deja a sus hijos huérfanos, sino que también puede llevar a enfrentar enormes riesgos, como el desamparo, el abandono y el maltrato; e incluso poner en peligro su propia supervivencia (1). La ausencia repentina y permanente de una madre en el hogar, constituye un factor de desequilibrio en la estructura familiar (2); a menudo los recién nacidos huérfanos son entregados a otros miembros de la familia (2); siendo los abuelos maternos, los que generalmente asumen este cuidado, representando en muchos casos desventaja social, dado el nivel de pobreza y la escasez de posibilidades que estos tienen para generar ingresos, incrementando de esta manera las posibilidades de subsistencia (3).
\end{abstract}

En Colombia, al igual que en muchos países de Latinoamérica, se han realizado diversos estudios que han identificado factores de riesgo asociados a la probabilidad de presentar una muerte materna $(4,5,6,7)$ entre ellos se destacan: el nivel educativo y el régimen de afiliación en salud (8); estas investigaciones, han señalado que la mortalidad materna es más frecuente en mujeres de baja escolaridad y pertenecientes al régimen subsidiado o sin ningún tipo de afiliación al sistema de salud (9). Adicionalmente, se han encontrado diferencias importantes en la mortalidad materna de acuerdo con la edad de la mujer, la zona de procedencia (rural/urbana), el estrato socioeconómico y la etnia (9). Podría concluirse que una muerte materna es el resultado final de una serie de factores y determinantes sociales que influyen en la vida de la mujer durante su etapa reproductiva, y estos pueden estar relacionados con el contexto sociocultural, las condiciones de salud de la mujer y el acceso a los servicios de salud durante la atención materna (10).

En el departamento de Córdoba, el contexto situado de la mortalidad materna se conceptualiza como aquellas condiciones del contexto que de manera directa o indirecta condicionan una defunción materna; circunstancias, que se encuentran relacionadas con la pobreza y la desigualdad social que enfrentan muchas mujeres de la región; especialmente, "la mujer pobre urbana", reconocida como aquella mujer, que aun viviendo en áreas de mayor desarrollo, presenta serias limitaciones para acceder de manera oportuna y segura a los servicios de salud, bien sea, por asuntos económicos, o aspectos relacionados con la falta de educación, la falta de autonomía y el desconocimiento para acceder a los métodos planificación familiar; además del sometimiento y violencia intrafamiliar a la que se ve enfrentada en su cotidianidad.

En un análisis crítico de la realidad social que enfrenta la mujer pobre urbana del departamento de Cordoba desde una pespectiva de género; se encontró un patrón común en las unidades de análisis de las muertes maternas relacionado con la falta de autonomía de la mujer, para decidir sobre sus procesos reproductivos. 
Bula Romero RJ. El contexto situado de la mortalidad materna en el departamento de Córdoba: Una fotografía de la Mujer pobre urbana

En nuestro contexto; generalmente, los hombres quieren que "estas mujeres" estén la mayor parte del tiempo o embarazadas, o con sus hijos en brazos, construcción social que representa a la mujer cordobesa de escasos recursos; aún si esta tiene, la posibilidad de acceder a los programas de regulación de la fecundidad y control de la natalidad. En general, parece existir un consenso de este imaginario social en la región, no obstante, el trasfondo de este asunto va más allá, de la mediación que existe, en las relaciones de poder entre hombres y mujeres, donde las mujeres ocupan un lugar subordinado.

La mortalidad materna en el departamento de Córdoba, más que un problema de salud pública es un asunto de justicia social hacia las mujeres; que requiere de políticas públicas claras, además de la participación activa de los entes territoriales, de la Academia y de los servicios de salud a quienes conmina a trabajar unidos para concentrar esfuerzos y mejorar la salud materna y perinatal de nuestro departamento; sabemos que el camino a recorrer no es fácil, pero bien vale la pena.

\section{Referencias}

1. Montero Sánchez, J. Arias, J; Rodríguez J. Mujeres que en proceso de dar vida la pierden: estudio cualitativo de la mortalidad materna en República Dominicana- Santo Domingo: Fundación Global Democracia y Desarrollo; Observatorio Político Dominicano, 2014.N56 p. - (Serie políticas públicas)ISBN: 978-9945-412-96-3

2. Ramírez Mejía Francisco, et al. Impacto de la mortalidad materna en la familia, especialmente en la niñez, de occidente de Honduras. Rev Med Hond 2003; 71:114122

3. Soto Mora Beatriz Helena. Análisis cualitativo de las muertes maternas en buenaventura 2010 - 2012 con enfoque de determinantes sociales y equidad. Universidad Nacional de Colombia Facultad de Medicina, Maestría en Salud Pública Bogotá, Colombia 2016.

4. Fantin y Zavattiero. Evolución y desigualdades de la mortalidad materna en Paraguay; algunos desafíos para su reducción. Población y Desarrollo. 2016; 22 (43): 2 - 1

5. Campero L, Walker D, Hernández B, Espinoza $\mathrm{H}$, Reynoso S, Langer A. La contribución de la violencia a la mortalidad materna en Morelos, México. Salud Pública Mex. 2006; 48 supl 2:S297-S306

6. Rodríguez L., Rodríguez A. Análisis de la mortalidad materna desde los determinantes sociales en los países de Latinoaméri-

1 Ph.D. (c) en Enfermería. Docente Universidad de Córdoba, Colombia. Correspondencia: javierbula@correo.unicordoba.edu. co ca y el Caribe. 2014. Mov.cient.Vol.6 (1): 132-143. Disponible en: https://revistas. iberoamericana.edu.co/index.php/Rmcientifico/article/view/165/0

7. Observatorio de Salud Sexual y Reproductiva. La vigilancia de las muertes maternas como herramienta para el logro del ODM 5. Buenos Aires: CEDES; CREP; IIE/ANM, 2010. 8 p. (Hojas Informativas, 4) Disponible en: http://www.ossyr.org.ar/hojas_informativas.html.

8. Vélez Gladis; Gómez Joaquín; Zuleta John. Análisis de las muertes maternas por hemorragia en el departamento de Antioquia, Colombia. Años 2004 y 2005. Revista Colombiana de Obstetricia y Ginecología, 2006, vol. 57, no 3.

9. Freyermuth Enciso M, 25 años de buenas prácticas para reducir la mortalidad materna en México. Experiencias de organizaciones de la sociedad civil y la academia; Observatorio de Mortalidad Materna en México: Centro de Investigaciones y Estudios Superiores en Antropología Social, 2015.

10. Rojas-Esguerra, Diego Fernando; Zarama-Tobar, Iris Lamar; Borrero-Ramírez, Yadira Eugenia; Arrivillaga-Quintero, Marcela Revisión de la producción académica latinoamericana sobre desigualdades en mortalidad 2007-2014 Revista Gerencia y Políticas de Salud, vol. 16, núm. 32, enero-junio, 2017, pp. 10-32 